\title{
Nanoparticle-Assisted Herbal Synergism an Effective Therapeutic Approach for the Targeted Treatment of Breast Cancer: A Novel Prospective
}

\author{
Majumder $\mathrm{P}^{*}$ \\ Department of Pharmacognosy and Phytochemistry, Acharya and BM Reddy College of Pharmacy, India
}

Submission: July 13, 2017; Published: August 03, 2017

*Corresponding author: Pulak Majumder, Department of Pharmacognosy and Phytochemistry, Acharya and BM Reddy College of Pharmacy, India, Tel: +917829807212; Email: pulak2007@gmail.com

\begin{abstract}
Combined therapy of two or more herbal drugs promotes synergism effect against cancer cells and suppresses drug resistance through distinct mechanisms of action. Permutation chemotherapy and nano-particulate drug delivery have shown significant promise in cancer treatment. Nano-formulated drug delivery enhances therapeutic effectiveness and reduces side effects of the chemotherapeutic drug-loads by improving their pharmacokinetics. These active researches have been merged further to improve the efficacy of cancer therapeutics. Agaricus bisporus and Syzygium aromaticum combined nano formulation may show an effective medicine for breast cancer treatment. Both the live species are commonly available and individually reported for its anti-neoplastic activities. Lectins obtained from Agaricus bisporus, a type of protein possessing high affinity for a specific sugar. Breast cancer growth stimulating enzyme aromatase suppress by lictin which turns to reduction of estrogen biosynthesis leads to inhibition of breast cancer. Similarly, Eugenol is the foremost component of Syzygium aromaticum, inhibit the cell proliferation and induce apoptosis in human breast cancer cells. This review article summarizes the herbal synergism associated with nanoparticle platforms to achieve a multi-drugs combination novel rational approach for the treatment of breast cancer.
\end{abstract}

Keywords: Syzygium aromaticum; Aromatase; Eugenol; Nanotechnology

Abbreviations: MDR: Multi-Drug Resistance; ABL: Agaricus Bisporus lectin; PNS-HLV: Panaxnotogin Senoside-Loaded core-shell Hybrid Liposomal Vesicles; PPARs: Peroxisome Proliferators-Activated Receptors; AB: Agaricus bisporus

\section{Introduction}

Cancer is one of the leading causes of death in world populations in various age and racial backgrounds. It has led to research and numerous clinical studies in an endeavour to limit the progression of this disease. Chemoprevention by dietary constituents has emerged as a novel advance to control cancer commonness. Breast cancer which is the second largest cause of death of women in worldwide. The drugs for treatment of breast cancer are still under investigation and pre-diagnosis also a costly affair. The approval rate for new oncology drugs is $\sim 5 \%$ in overall cancer research. Cheap and effective medication is a cutting age demand for breast cancer. Breast cancer is a major public health problem in developed countries like the United States and intensifying issue in India as well $[1,2]$. It is the most widespread cancer in women and the leading cause of cancer death among women 25-60 years of age [3].

The international agency for research on cancer estimates 4,11,000 deaths occur among 1.15 million diagnosed cases in worldwide [4]. The growing incidence and poor prognosis of breast cancer cases have prompted a search for auxiliary preventive and the therapeutic modalities [5]. Cancer cells often express several normal proteins on the cell surface in larger amounts than the normal cells, and these meticulous over expressed proteins on cancer cells are extraordinary targets for active targeting. The efficient targeting nanoconstructs can standby the neighboring normal healthy cells to a definite extent. One of the most noteworthy perceptions is the development of multifunctional nano-carriers that comprise a high freight of drugs or imaging moieties, which bind to specific proteins that are over expressed in cancer cells [6-8].

Herbal medicine can be used to target individual organ by association with nanoparticle which improves the selectivity and drug delivery, effectiveness and reduces therapeutic dose with better patient compliance and more eventually reduces side effect. An ideal nano particulate system is that it should 


\section{Global Journal of Nanomedicine}

be capable of circulating in blood stream and should be small enough to reach target cells and tissues $[9,10]$. This review is a novel approach to focus on herbal synergism associated with nano particulate drug delivery system to achieve a multi-drugs combination novel rational chemotherapeutic approach towards breast cancer treatment.

\section{Herbal synergism on cancer therapy}

Permutation chemotherapy for anticancer treatment has shown potential strategy to generate synergistic anticancer effects, lessen individual drug-related toxicities, restrain multidrug resistance (MDR) through different mechanisms of action, and reduce the dose of each agent required [11,12]. It refers to the simultaneous administration of two or more active agents to modulate diverse signaling pathways in tumor cells, to provoke cell cycle arrest in a different phase of the cell cycle, to exploit the treatment effect and to prevail over MDR [13]. Recently, several reviews pertaining to nano-sized carriers deliberate for combination drug delivery in cancer chemotherapy [14-17]. One of the leading limitations of prevailing cancer therapies is the deficiency of specificity of anticancer drug delivery; therefore, most anti-cancer drugs have adverse cytotoxic effects on regular healthy cells. There is an increasing demand for the advance and efficient delivery of drugs to the targeted site to achieve the potential therapeutic action $[18,19]$.

\section{Agaricus bisporus}

Agaricus bisporus commonly known as button mushroom, white mushroom, table mushroom, portobello mushroom, Crimini mushroom or cultivated mushroom etc [20]. It is an edible basidiomycete mushroom inhabitant to grasslands in India, Europe and North America [21]. Agaricus bisporus is one of the most extensively cultivated mushrooms in the world [22]. The unique wild form of Agaricus bisporus has borne with a brownish cap and dark brown gills but more well-known is the current variant with white cap, stalk and flesh and brown gills [23] (Figure 1).
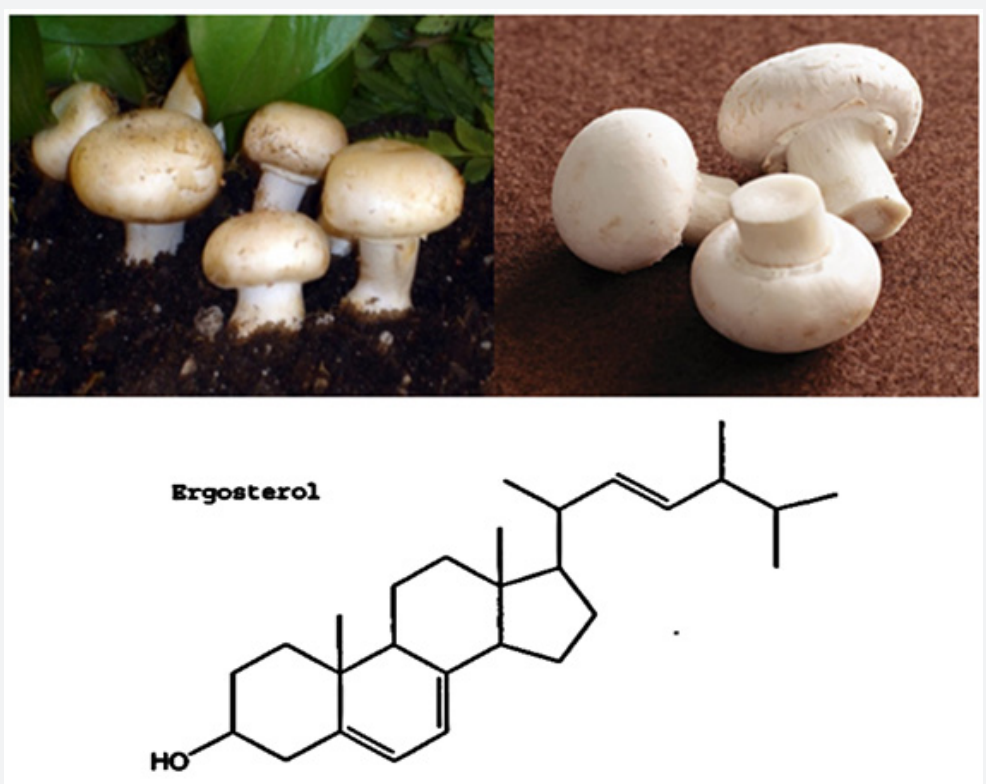

Figure 1: Agaricusbisporus and structure of Ergosterol.

Chemical composition: Agaricus bisporus contains 1-20\% unfinished fat of total dry weight. Besides protein, a large variety of free and combined fatty acids are present in high concentrations. They are palmic acid, stearic acid and oleic acid [24]. The foremost active compound like unsaturated fatty acids such as linoleic acid, linolenic acid and conjugated linoleic acid were found in the ethyl acetate fraction [25]. Fresh mushroom contains 3-28\% of carbohydrates, pentoses, hexoses, disaccharides and trehlose like various mushroom sugars [26]. Various essential amino acids like methionin, citralline, ornithin etc, Thiamin, riboflavin, niacin, biotin, ascorbic acid, vitamin A, B, C, D and minerals like sodium, potassium, calcium, iron, etc. are found prominently in Agaricus bisporus. Lectins are a diverse group of carbohydrate-binding proteins commonly present in Agaricus bisporus. Lectins can act as mediators of cellular and molecular recognition in a wide range of biological systems [27]. Agaricus bisporus is a good source of trace elements like sodium, potassium, and phosphorus, conjugataed linoleic acid [28]. Phenols were the major antioxidant components found in the Agaricus extracts [29]. Mushrooms endow with more selenium than other foods in the fruit and vegetables [30].

\section{Biological functions of Agaricus bisporus}

In cancer treatment: Agaricus bisporus extract can inhibit the activity of aromatase and therefore may be able to subordinate the estrogen levels in the human body, which might 


\section{Global Journal of Nanomedicine}

reduce breast cancer vulnerability [31]. Aromatase is an enzyme that converts androgen to oestrogen. Amplified expression of aromatase in breast tissue is considered to be a risk factor for breast cancer. Small molecule exerting from Mushroom showed direct cytotoxicity in relation with antioxidant compounds like phenol and flavonoids have verified that chemotherapy induced apoptosis and subsequent phagocytosis of cancer cells depends on the redox status and the intracellular equilibrium between pro and antioxidants [32]. The phenolic chemical constituent Ergosterol, obtained from white button mushroom showed inhibitory effect on breast cancer cell line in-vitro by aromatase inhibition without side effect [33]. Agaricus bisporus lectin (ABL) has potent anti-proliferative effects on human epithelial cancer cells, without any perceptible cytotoxicity.

This property confers to it a significant therapeutic potential as an anti-neoplastic agent [34]. ABL caused a dose-dependent reticence of proliferation and lattice retrenchment without significant toxicity. ABL might be particularly useful where slight modification of healing is needed, as in eye surgery for glaucoma [35,36]. Agaricus bisporus contains Selenium plays a possible role to prevent cancer through anti-oxidant protection or may increase immune function. There is evidence from human studies to advocate that selenium may reduce the incidence of cancer when taken in elevated doses. Intervention trials have also confirmed the benefit with selenium in tumbling cancer, specifically in the liver, prostate, colon, and lung with the supreme benefits in those with lowly selenium status [37].

Agaricus bisporus chemical compounds would act in combination to influence cell surface receptors and to prompt diverse downstream signaling events foremost to high pharmacological efficiency and specificity [38]. In 2009, a case control study of over 2000 women correlated a large decrease of breast cancer prevalence in women who consumed mushrooms regularly. Daily intake of fresh mushrooms, were reported to be $64 \%$ reduction of enlarge breast cancer, in the other hand mushroom diet with regular green tea consumption, condensed their risk of breast cancer by virtually $90 \%$. It possesses probable immune system enhancing properties [39]. The constituents of mushroom along with antioxidants from green tea may hold the key of this potential property (Table 1).

Table 1: Overview of Agaricusbisporus in cancer treatment.

\begin{tabular}{|c|c|c|}
\hline Chemical Substance & Benefits & Mechanism of Action \\
\hline \multirow{4}{*}{ Lectin } & Inhibit the growth of tumor & $\begin{array}{l}\text { TML-1 \& TML-2, stimulate the production of nitrate ions } \\
\text { and activated macrophages. }\end{array}$ \\
\hline & $\begin{array}{l}\text { Cytotoxic activity against human tumor cells, Brest cancer } \\
\text { and sarcoma cells. }\end{array}$ & $\begin{array}{c}\text { Block the import of protein into nucleus and inhibit cell } \\
\text { proliferation. }\end{array}$ \\
\hline & Anti-proliferative action. & $\begin{array}{c}\text { Breast and hepatoma cancer cells are Anti-proliferative } \\
\text { with IC }(50) \text { of } 2.1 \mu \mathrm{M} .\end{array}$ \\
\hline & Tumor suppression action & $\begin{array}{c}\text { Dimerization of AAL is a prerequisite for cell apoptosis } \\
\text { inducing activity. }\end{array}$ \\
\hline \multirow{2}{*}{$\beta$ Glucan } & Tumoricidal activity & $\begin{array}{l}\text { Tumor cell growth inhibited directly by inducing } \\
\text { apoptotic processing. }\end{array}$ \\
\hline & Enhances the immune system & Stimulate the cytokinins by T cells and increase NK cells. \\
\hline \multirow{3}{*}{ Ergosterol } & Anti tumor activity & Decrease the tumor size by cytotoxicity. \\
\hline & Anti- migratory effect & $\begin{array}{l}\text { Ergosterol peroxide and daucosterol inhibited the } \\
\text { migration of MDA-MB-231 cells. }\end{array}$ \\
\hline & Anti-proliferative action & Cytotoxicity against the human breast cancer. \\
\hline Arginine & Tumor growth inhibition, reduce Nitrogen loss & $\begin{array}{l}\text { Increase the number of NK cells and } \mathrm{T} \text { cells, increase } \\
\text { immunity through release of growth hormone and } \\
\text { produces nitric oxide, hydroxyproline and polyamines. }\end{array}$ \\
\hline
\end{tabular}

Syzigium aromaticum (Eugenol): Syzigium aromaticum frequently known as cloves, has the foremost biologically active phenolic constituent 4-allyl-2-methoxyphenol or Eugenol has been used traditionally in Asian countries, mainly as a medicinal antiseptic, analgesic, antibacterial, flavoring agent, and also plays a role in dentistry as cavity filling cement. Eugenol posse's diverse pharmacological properties like antiviral, antioxidant, anti-inflammatory etc [40-43]. At low concentrations, eugenol usually acts as an antioxidant and anti-inflammatory agent $[44,45]$. It has also been reported as anti-genotoxic agent [4648]. Eugenol along with trans-anethol shows antigenotoxic property next to chemicals like cyclophosphamide, procarbazine and urethane (Figure 2). 

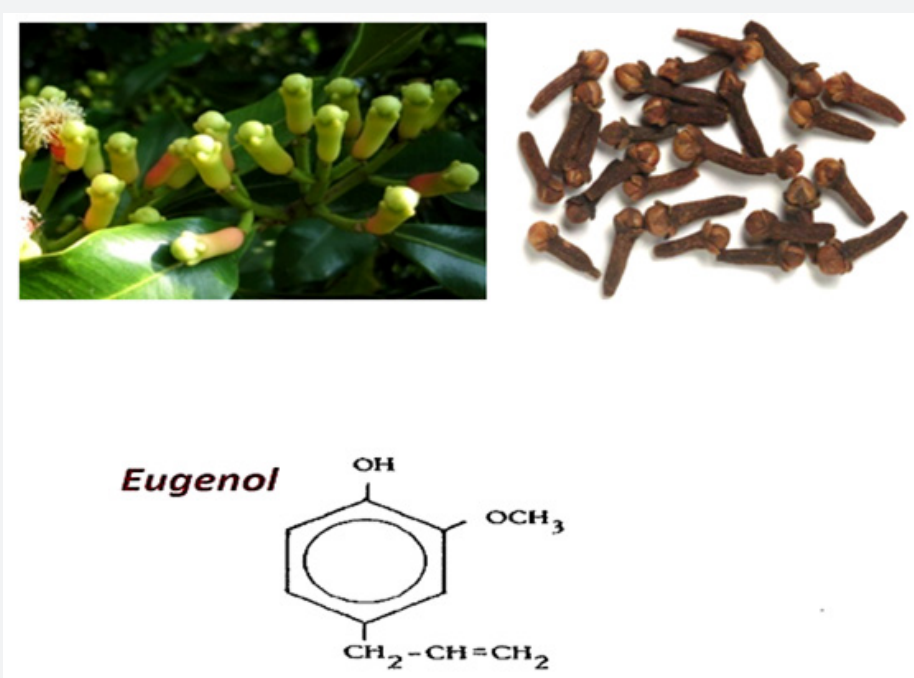

2. RUPAC Name

4-allyl-2-methoxyplienol
$\mathrm{C}_{10} \mathrm{H}_{12} \mathrm{O}_{2}$

3. Molecular formula =

4. Molecular weight

Figure 2: Syzigiumaromaticum and Chemical structure of Eugenol.

Chemistry and structure of eugenol: Clove essential oil contains almost $72-90 \%$ eugenol. Eugenol is a member of the allyl-benzene class of chemical compounds i.e. guaiacol, anallyl chain-substitute. Guaiacol is naturally occurring organic compound with the formula $\mathrm{C} 6 \mathrm{H} 4(\mathrm{OH})(\mathrm{OCH} 3)$. It is a clear to pale yellow oily liquid, generally well soluble inorganic solvents and sparingly soluble in water with Spicy pungent taste.

\section{Anti-proliferative mechanism of eugenol against melanoma cells}

Eugenol and six of its derivatives are found to be effective in anti-proliferative activity against primary melanoma cell lines [42]. Dimeric biphenyls of dehydrodieugenol decrease about $40-60 \%$ cell growth rate. Growth inhibition by $70-80 \%$ showed by $0,0^{\prime}$-dimethyldehydrodi eugenol against the melanoma cells whereas the 6,6'-dibromodehydrodieugenol induced a fairly complete growth inhibition (nearly 100\%) against the tested melanoma cell lines.

Apoptosis in human melanoma cells is induces by Eugenol [49]. Eugenol and isoeugenol act as an anti-proliferative agent against malignant melanoma cells [50,51]. Eugenol is found to be more potent agent in inhibiting melanoma cell lines compared to Isoeugenol. Cell cycle changes associated with the eugenol showed cells blocked at S-phase accompanied by the reduction in the G1 phase cells with no significant change in the G2/M phase cells. About $75 \%$ of proliferation ability restored in cultures, signifying that, eugenol could be build up as an E2Ftargeted agent for melanoma treatment. Eugenol inhibits the cell proliferation and initiation of apoptosis in human MCF-7 breast cancer cells. Eugenol inhibit the growth and propagation of human MCF-7 breast cancer cells through induction of cell death, by dose and time dependent manner [51].

Antioxidant action of eugenol: Eugenol have a methoxyphenolic structure interferes with initiation as well as propagation of lipid peroxidation and it is attributed to free radical scavenging effect of eugenol [52]. Eugenol has double role i.e. pro-oxidant and antioxidant. Thus, intake of these compounds may assist to avert in-vivo oxidative damage, such as lipid peroxidation, which is allied with many diseases like cancer, arteriosclerosis, diabetes, and immune deficiency. The pro-oxidant activity of eugenol, causes cytotoxicity [53]. Eugenol at the low dose almost $2 \mu \mathrm{M}$ has specific toxicity against diverse breast cancer cells. This effect was mediated mainly through inducing the intrinsic apoptotic pathway and strong downregulation of E2F1 followed by its downstream anti-apoptotic target survive in, independently of the status of p53 and ER $\alpha$. Eugenol also repressed several other breast cancer related oncogenes, such as NF- $\kappa \mathrm{B}$ and cyclin D1.

The up-regulation of the adaptable cyclin-dependent kinase inhibitor p21WAF1 protein and repressed the cell proliferation in breast cancer in a p53-independent manner by eugenol. Significantly, these anti-proliferative action and pro-apoptotic effects were also notice in-vivo in xeno-grafted human breast tumors also. The anti-breast cancer activity of Eugenol signifying led to its combine use in the adjuvant treatment of breast cancer through targeting the E2F1/surviving pathway [54].

\section{Modern nano technology based drug delivery and cancer therapy}

Nano-biotechnology is the most advancing field of nano- 
science which involves nanoparticles for various biomedical applications and especially therapeutic treatment for cancers as well [55]. Biologically uniqueness of nanoparticles exhibits the different molecular advances from traditional minute molecules to complicated advance drugs [56]. Nanomaterials aids the targeted delivery, sustained delivery and improves the pharmacokinetics profile, diffusion of drugs into various organs by crossing the barriers including the blood brain barrier.

The biggest drawback in modern treatment for cancers therapy is larger side effects and fabricates toxicity to both cancer and normal cells. Even chemotherapy is often limited by important side effects and is nonspecific to cancer or tumor cells, leading to serious damage to healthy cells [57]. Nanoparticles coated with natural isolated drugs are implemented as drug delivery for cancer treatment because of their intrinsic physical properties and their capability to target specific cancer tissues and prevent toxicity to healthy tissues $[58,59]$. Iron oxide nanoparticles are extensively used for drug delivery agents in cancer diagnosis [60]. Reactive oxygen species induced by nanoparticles creating an oxidative stress on the cell which consequences in cytotoxicity. Oxidative stress caused nanoparticles harms DNA and also damage genetic contents which direct to apoptosis. Nanoparticles coated with the polymer membrane illustrate promising decrease or decline in the toxicity and it is widely followed in the field of drug delivery [61].

\section{Discussion}

Development of nano formulations, where conversion of phytomedicine into nano phytomedicine by reducing the size. The modification of surface properties of phytomedicine increases the aqueous solubility and permeability through biological barriers. Different nano carriers like Liposomes, niosomes, nanospheres and phytosomes have the ability of delivering herbal drugs efficiently to the target area. Herbal drugs amalgamation in the delivery system gives support to increase solubility, enhance stability, protect from toxicity, enhance pharmacological activity, improve tissue macrophage distribution, sustain delivery and protect from physical and chemical degradation.

The utilization of nanotechnology likely to accomplish various effects like targeted delivery of phytomedicine in specific cell- or tissue, improvement of drug delivery in poorly watersoluble phytomedicine, phytomedicinal transcytosis towards tight epithelial and endothelial barriers, macro molecular phytomedicine delivery to intracellular sites of action, codelivery of two or more phytomedicines or therapeutic modality for combination therapy and incorporating phytomedicine with imaging modalities for observation of sites of drug delivery. Numerous studies have been reported for different nano carriers for phytomedicine delivery. Recently, nano emulsified ethanolic extract of PhyllanthusamarusSchum \& Thonn ameliorated illustrated that the nano-phytomedcine formulation showed better hepatoprotective activity than Phyllanthusamarus Schum and also repeated dose in oral toxicity proved to be safe [62]. Restricted bioavailability has been resolve in Panaxnotogin senoside-loaded core-shell hybrid liposomal vesicles (PNSHLV) and also enhance its protective effects in-vivo on oral administration. HLV has promising prospects for improving free drug bioactivity on oral administration [63].

For the use of oral delivery, Solid lipid nanoparticles of frankincense and myrrh essential oils by a high-pressure homogenization method using Compritol 888 ATO as the solid lipid and soybean lecithin and Tween 80 as the surfactants could be used as drug carriers for hydrophobic oil drugs extracted from traditional Chinese medicines [64]. On the basis of those studies, it can be predicted that, the combination of Agaricus bisporus and Syzygium aromaticum in the form of nano-formulation may show an effective therapy for breast cancer treatment with lesser side effect. Eventually both the live species are very commonly available and individually reported for its anti-neoplastic activities. Moreover, the materialization of substantially more effective, less toxic and less costly new therapy for breast cancer become very sluggish. All existing therapies hit $<500$ molecular targets, signifying that there are many unexplored targets for drug discovery within the human interactome which comprises possibly 1 million proteins and over 1 trillion potential interconnections. Effective phyto-constituent like eugenol and various fatty acids combination will leads to destroy cancer cell more prominently with significantly lower dose compared to the individual approach. This novel approach may lead to a beneficial out come in the field of modern breast cancer therapy.

The predicted synergistic mechanism of action behind this combination likely to be based on Estrogen synthase enzyme or Aromatase or the cytochrome P450 enzyme complex that converts C19 androgens to C18 estrogens. Estrogens engage in recreation a significant role in breast cancer development. Aromatase is articulated at an elevated level in human breast cancer tissue rather than in normal breast tissue. In-situ production of estrogenmay plays a major role than circulating estrogens in breast tumor progression. Enzyme aromatase stimulate breast cancer growth in both an autocrine and a paracrine manner. In-situ estrogen biosynthesis suppression can be achieved by the obstacle of aromatase expression or aromatase inhibitory activity in breast tumors. Even as today, it is not fully understood the aromatase expression mechanism in breast cancer tissue.

Generally, the patients who fails anti-estrogen therapy are treated with Aromatase-inhibitor as considered as second-line therapy. Phytoestrogens are found to be inhibitor of estrogen biosynthesis in breast tissue. Local regulation of enzyme aromatase controls the levels of estrogen accessible for breast cancer growth. The Intracellular cAMP levels increases by 


\section{Global Journal of Nanomedicine}

prostaglandin PGE2 and stimulates estrogen biosynthesis, and linear association between aromatase (CYP19) expression and expression of the cyclooxygenases (COX-1 and COX-2) in breast cancer. Enhanced COX enzyme levels result in increased production of prostaglandins, such as PGE2. This prostaglandin amplified aromatase activity in breast stromal cells, and EP1 and EP2 receptor subtypes directs the signalling pathways. COX-2 gene expression was improved in breast cancer cell lines by ligands for the diverse peroxisome proliferators-activated receptors (PPARs) and hormone-dependent and -independent breast cancer cell regulations observed and both enzymes in breast cancer involves complex paracrine interactions, consequential in significant consequences on the pathogenesis of breast cancer [57]. Nitric oxide and peroxynitrite, the duo product of nitric oxide and Superoxide increases the COX-2 activity in the murine macrophage cell line [65].

In addition, LPS and interleukin-1 induced COX-2 expression has decreased after antioxidant treatment of rat mesangial cells and alveolar macrophages, respectively [66]. Diverse antioxidants on intra-cellular redox condition, COX-2 expression and role in human CRC cell line HCA-7 are inter-related these changes with possessions on cellular proliferation. COX-1 and COX-2 are expressed and produce huge amounts of prostaglandins (PGs) in HCA-7 cells [67]. Antioxidants significantly reduce PG production and proliferation of cell line. The decrease in call proliferation is due to introduction of G phase, cell cycle arrest and/or apoptosis.

Permutation therapy is the most effective treatment strategy in cancer to prevail over drug toxicity and drug induced resistance. Eugenol in combination with 5 -fluorouracil exhibited more cytotoxicity against the cervical cancer cells and amplified the number of cells in the $\mathrm{S}$ and G2/M phases when compared to alone individual compounds treatment. This indicated that eugenol possessed different cell cycle targets and induced apoptosis in the cancer cells [68]. Eugenol and its chemically synthesized derivatives proved its activity against melanoma, skin tumors, prostate cancer, gastric cancer and leukemia via oncogene regulation and caspase dependent pathways [69]. Agaricus bisporus (AB) contains Lectin, $\beta$ Glucan, Ergosterol, Arginine etc. are a potential chemo-preventive, Anti-proliferative agent in breast cancer; by suppress aromatase enzyme activity and estrogen biosynthesis. Its potent activity is mainly due to the presence of its active compound lectin [70]. Lectin and polysaccharides found in white button mushrooms may inhibit tumorigenesis by stimulate the immune system.

The phyto-constituent present in mushroom extracts inhibits the cancer cell proliferation and prevents tumor growth. Antioxidants also have anti-tumor properties and coadministration of $\beta$-carotene and $\alpha$-tocopherol led to greater tumor degeneration. The synergistic effect found much better than the sum of the mild tumor inhibition of beta-carotene and alpha-tocopherol [70]. The combination of Agaricus bisporus
(Lectins) and Syzigium aromaticum contains chief chemical Eugenol i.e. aromatase reductase and antioxidant may lead to be a novel rational combination for breast cancer. Strong relationship exists between antioxidant in COX-2 inhibition and aromatase enzyme reductase in relation with cancer suppression. In cooperation of those components may possess synergistic action as resulted potent breast cancer treatment. Therapeutic nanoparticles co-encapsulating multiple drugs are more active against cancer cells. Targeted delivery toward the breast cancer is therefore an imperative element in the advance of nanoparticle-based combination therapy. Nanoparticles can passively gather at the tumor site through improved permeability and retention effects, active targeting can be added aid the route. Surface functional groups containing liposomes, polymeric nanoparticles and dendrimers may be conjugated to targeting ligands for specific drug delivery.

\section{Conclusion}

This study focused on designing and development of multifunctional phytonanomaterials and their formulations. The prospect of this combination in nanoparticle platforms may able to yield desired medical solution for the effective treatment of breast cancer. The rational use of aromatase enzyme inhibitor along with antioxidants from both the phyto sources may carry the significant clinical consequences in breast cancer treatments and mostly by avoiding larger side effects with the aid of modern nano technological tools.

\section{Future perspective}

Recently in worldwide the basic and clinical trials are being carried out to develop herbal remedies in the drug delivery system and bounce sack from side effects like toxicity and hypersensitivity reactions. The concept of herbal nano particulated drug delivery for cancer may also enthral some potential research groups and potentially create attentiongrabbing results. Herbal remedies in the nanocarriers increases its potential for the treatment of various chronic diseases and health welfares. Phyto constituents are the affluent resources of beneficial compounds antioxidants and constituents that can be made use in purposeful foods. This combined research with phyto constituents and modern drug delivery system has established the attractive therapies to the pharmaceuticals in future.

The effectual and valuable significance of the natural products and Phyto remedies being applied with the nanocarrier enhance the significance of prevailing drug delivery systems. Nanoparticle drug delivery has control over the pharmacokinetics of chemotherapeutic agents. Development of nano particulated combination therapy has several unique features that are untenable in traditional chemotherapy. This study has envisioned that more therapeutic nanoparticles containing multiple drugs with precise drug dosage and release profiles will be developed to treat various cancer. In addition, 


\section{Global Journal of Nanomedicine}

emerging techniques in drug-polymer conjugations and nanomaterials engineering continue to expand the nanoparticle platforms on which better therapeutic regimens may design.

\section{Acknowledgement}

The author is thankful to the Principal, Acharya and BM Reddy college of Pharmacy, Bangalore, for providing adequate facilities and extends sincere gratitude to Dr. Manjunath PM, Dept. of Pharmacology, Acharya and BM Reddy college of Pharmacy, for his precious suggestions for grounding this work.

\section{References}

1. Mitra AK, Faruque FS (2004) Breast cancer incidence and exposure to environmental chemicals in 82 counties in Mississippi. South Med J 97(3): 259-263.

2. Desai SB, Moonim MT, Gill AK, Punia RS, Naresh KN, et al. (2000) Hormone receptor status of breast cancer in India: A study of 798 tumours. Breast 9(5): 267-270.

3. Brody JG, Moysich KB, Humblet O, Attfield KR, Beehler GP, et al. (2007) Environmental pollutants and breast cancer: Epidemiologic studies. Cancer 109(12): 2667-2711.

4. Smith RA, Caleffi M, Albert US, Chen TH, Duffy SW, et al. (2006) Breast cancer in limited-resource countries: Early detection and access to care. Breast J 12(Suppl.1): S16-S26.

5. Wang X, Wei Y, Yuan S, Liu G, Lu Y, et al. (2005) Potential anticancer activity of tanshinone IIA against human breast cancer. Int J Cancer 116(5): 799-807.

6. Moghimi SM, Peer D, Langer R (2011) Reshaping the future of nanopharmaceuticals: Ad Iudicium. ACS Nano 5(11): 8454-8458.

7. Xiao Z, Levy-Nissenbaum E, Alexis F, Lupták A, Benjamin AT, et al (2012) Engineering of targeted nanoparticles for cancer therapy using internalizing Aptamers isolated by cell-uptake selection. ACS Nano 6(1): 696-704.

8. Perfézou M, Turner A, Merkoçi A (2012) Cancer detection using nanoparticle-based sensors. Chem Soc Rev 41(7): 2606-2622.

9. Allen TM, Cullis PR (2004) Drug delivery systems: entering the mainstream. Science 303(5665): 1818-1822.

10. Kostarelos K (2003) Rational design and engineering of delivery systems for therapeutics: biomedical exercises in colloid and surface science. Adv Colloid Interface Sci 106: 147-168.

11. Wang H, Zhao Y, Wu Y, Hu YL, Nan K, et al. (2011) Enhanced anti-tumor efficacy by co-delivery of doxorubicin and paclitaxel with amphiphilic methoxy PEG-PLGA copolymer nanoparticles. Biomaterials 32(32): 8281-8290.

12. Parhi P, Mohanty C, Sahoo SK (2012) Nanotechnology-based combinational drug delivery: an emerging approach for cancer therapy. Drug Discov Today 17(17-18): 1044-1052.

13. Greco F, Vicent MJ (2009) Combination therapy: opportunities and challenges for polymer-drug conjugates as anticancer nanomedicines. Adv Drug Deliv Rev 61(13): 1203-1213.

14. Matsumura Y, Maeda (1986) A new concept for macromolecular therapeutics in cancer chemotherapy: mechanism of tumoritropic accumulation of proteins and the antitumor agent smancs. Cancer Res 46(12): 6387-6392

15. Brannon-Peppas L, Blanchette JO (2004) Nanoparticle and targeted systems for cancer therapy. Adv Drug Deliv Rev 56(11): 1649-1659.
16. Northfelt DW, Dezube BJ, Thommes JA, Miller BJ, Fischl MA, et al. (1998) PEGylated-liposomal doxorubicin versus doxorubicin, bleomycin and vincristine in the treatment of AIDS-related Kaposi's sarcoma: results of a randomized phase III clinical trial. J ClinOncol 16(7): 2445-2451.

17. Harries M, Ellis P, Harper P (2005) Nanoparticle albumin-bound paclitaxel for metastatic breast cancer. J ClinOncol 23(31): 7768-7771.

18. Hong H, Yang K, Zhang Y, Engle JW, Feng L, et al. (2012) In vivo targeting and imaging of tumor vasculature with radiolabelled, antibodyconjugated nanographene. ACS Nano 6(3): 2361-2370.

19. Sasidharan A, Chandran P, Menon D, Raman S, Nair S, et al. (2011) Rapid dissolution of $\mathrm{ZnO}$ nanocrystals in acidic cancer microenvironment leading to preferential apoptosis. Nanoscale 3(9): 3657-3669.

20. Have RT, Wijngaard H, Ariës-Kronenburg NA, Straatsma G, Schaap PJ (2003) Lignin degradation by Agaricusbisporusaccounts for a 30\% increase in bioavailable holocellulose during cultivation oncompost. Agric Food Chem 51(8): 2242-2255.

21. Hood PN, Beets MO, Kimberley JF (2004) Colonisation of podocarp coarse woody debris by decomposer basidiomycete fungi in an indigenous forest in the central North Island of New Zealand. Forest Ecology and Management 196: 311-325.

22. Grove JF (1981) Volatile compounds from the mycelium of the mushroom Agaricusbisporus. Phytochem 20: 2021-2032.

23. Parslew R, Jones KT, Rhodes JM, Sharpe GR (1999) The antiproliferative effect of lectin form the edible mushroom (Agaricusbisporus) on human keratinocytes: preliminary studies on its use in psoriasis. $\mathrm{Br} \mathrm{J}$ Dermatol 140(1): 56-60.

24.Sadler M (2003) Nutritional properties of edible fungi. British Nutrition Foundation Nutrition Bulletin 28(3): 305-308.

25. Regina PZF, Helena TG (2008) Vitamins B1 and B2 contents in cultivated mushrooms. Food Chem 106: 816-819.

26. Irazoqui FJ, Zalazar FE, Nores GA, Vides MA (1997) Agaricusbisporuslectin binds mainly Oglycans but also N-glycans of human IgA subclasses. Glycoconjugate J 14(3): 313-319.

27. Presant CA, Kornfeld S (1972) Characterization of the cell surface receptor for the Agaricus bisporus hemagglutinin. J BiolChem 247(21): 6937-6945.

28. Shiuan C, Sheryl P, Gene H, Sharon K, Jingiing Y, et al. (2005) Breast cancer prevention with phytochemicals in mushrooms. Proc AmerAssoc Cancer Res 65(9): 5186.

29. Andrera AS, Cristina G, Marques D, Francielle MD (2009) Antioxidant activity and total phenolic content of Agaricusbrasiliensis (AgaricusblazeiMurril) in two stages of maturity. Food Chem 112: 775781

30. Clark LC, Combs GF, Turnbull BW, Slate EH, Chalker DK, et al. (1996) Effects of selenium supplementation for cancer prevention in patients with carcinoma of the skin, A randomized controlled trial. Nutritional Prevention of Cancer Study Group. JAMA 276(24): 1957-1963.

31. Winer EP, Hudis C, Burstein HJ, Wolff AC, Pritchard KI, et al. (2002) American Society of Clinical Oncology technology assessment of the use of aromatase inhibitors as adjuvant therapy for women with hormone receptor positive breast cancer: Status report 2004. J Clin Oncol 23(3): 619-629.

32. Kenta B, Sheridana C, Tomkinsona HA, Whitec S, et al. (2008) Antioxidant activity of Agaricus sp. mushrooms by chemical, biochemical and electrochemical assays. Food Chem 111: 61-66.

33. Kent D, Sheridan C, Tomkinson HA, White S, Hiscott P, et al (2002) Edible mushroom (Agaricusbisporus) lectin modulates human retinal pigment epithelial cell behaviour in-vitro. Exp Eye Res 76(2): 213-219. 


\section{Global Journal of Nanomedicine}

34. Batterbury M, Tebbs CA, Rhodes JM, Grierson I (2002) Agaricusbisporus (edible mushroom lectin) inhibits ocular fibroblast proliferation and collagen lattice contraction. Exp Eye Res 74(3): 361-370.

35. Yu LG, Fernig DG, White MR, Spiller DG, Appleton P, et al. (1999) Edible mushroom (Agaricusbisporus ) lectin, which reversibly inhibits epithelial cell proliferation, blocks nuclear localization sequencedependent nuclear protein import. J BiolChem 274(8): 4890-4899.

36. Spolara MR, Schafferb EM, Beelmana RB, Milnerb JA (2006) Seleniumenriched Agaricusbisporus mushrooms suppress 7,12-dimethlybenz[a] anthracene bio activation in mammary tissue. J Chromatography 1101 : 94-102.

37. Zhi-qiang L, Jian-hong Z, Yun-long Z, Xu-long O (2004) The enhancement and encapsulation of Agaricusbisporus flavour. J Food Engineering 65: 391-396.

38. Loganathan KJ, Venkata k, Shenbhagaraman R, Kaviyarasan V (1994) Comparative study on the antioxidant, antioxidant and antimicrobial property of Agaricusbisporus(J,E,Lange) imbach before and after boiling. Phytochem 35: 573-577.

39. Pisano M, Pagnan G, Loi M, Mura ME, Tilocca MG, et al. (2007) Antiproliferative and pro-apoptotic activity of eugenol-related biphenyls on malignant melanoma cells. Mol Cancer 6: 8 .

40. Ogata M, Hoshi M, Urano S, Endo T (2000) Antioxidant activity of eugenol and related monomeric and dimeric compounds. Chem Pharm Bull 48(10): 1467-1469.

41. Benencia F, Courreges MC (2000) In-vitro and In-vivo activity of eugenol on human herpesvirus. Phytother Res 14(7): 495-500.

42. Chogo JB, Crank G (1981) Chemical composition and biological activity of the tanzanian plant Ocimum suave. J Nat Prod 44(3): 308-311.

43. Sun XZ, Zhou D, Chen S (1997) Autocrine and paracrine actions of breast tumor aromatase. A three-dimensional cell culture study involving aromatase transfected MCF-7 and T-47D cells. J Steroid Biochem Mol Biol 63(1-3): 29-36.

44. Asha MK, Prashanth D, Murali B, Padmaja R, Amit A (2001) Anthelmintic activity of essential oil of Ocimum sanctum and eugenol. Fitoterapia 72(6): 669-670

45. Miyazawa M, Hisama M (2001) Suppression of chemical mutagen-induced SOS response by alkylphenols from clove (Syzygiumaromaticum) in the Salmonella typhimurium TA1535/ pSK1002. J Agric Food Chem 49(8): 4019-4025.

46. Han EH, Hwang YP, Jeong TC, Lee SS, Shin JG, et al. (2007) Eugenol inhibit 7,12-dimethylbenz[a]anthracene-induced genotoxicity in MCF-7 cells: Bifunctional effects on CYP1 and NAD (P) H:quinone oxidoreductase. FEBS Lett 581(4): 749-756.

47. Abraham SK (2001) Anti-genotoxicity of trans-anethole and eugenol in mice. Food Chem Toxicol 39(5): 493-498.

48. Kim GC, Choi DS, Lim JS, Jeong HC, Kim IR, et al. (2006) Caspasesdependent apoptosis in human melanoma cell by eugenol. Korean J Anat 39: 245-253.

49. Ghosh R, Nadiminty N, Fitzpatrick JE, Alworth WL, Slaga TJ, et al. (2005) Eugenol causes melanoma growth suppression through inhibition of E2F1 transcriptional activity. J Biol Chem 280(7): 5812-5819.

50. Vidhya N, Devaraj SN (2011) Induction of apoptosis by eugenol in human breast cancer cells. Indian J Exp Biol 49(11): 871-878.

51. Nagababu E, Lakshmaiah N (1994) Inhibition of microsomal lipid peroxidation and Monooxygenase activities by eugenol. Free Radic Res 20(4): 253-266

52. Fujisawa S, Atsumi T, Kadoma Y, Sakagami H (2002) Antioxidant and prooxidant action of eugenol-related compounds and their cytotoxicity. Toxicology 177(1): 39-54.
53. Al-Sharif I, Remmal A, Aboussekhra A (2013) Eugenol triggers apoptosis in breast cancer cells through E2F1/survivin downregulation. BMC Cancer 13: 600 .

54. Yezhelyev MV, Gao X, Xing Y, Al-Hajj A, Nie S, et al. (2006) Emerging use of nanoparticles in diagnosis and treatment of breast cancer. Lancet Oncol 7(8): 657-667.

55. Wagner V, Dullaart A, Bock AK, Zweck A (2006) The emerging nanomedicine landscape. Nat Biotechnol 24(10): 1211-1217.

56. Brigger I, Dubernet C, Couvreur P (2002) Nanoparticles in cancer therapy and diagnosis. Adv Drug Deliv Rev 54(5): 631-651.

57. Brown SD, Nativo P, Smith JA, Stirling D, Edwards PR, et al. (2010) Gold nanoparticles for the improved anticancer drug delivery of the active component of oxaliplatin. J Am ChemSoc 132(13): 46784684

58. Liu Y, Miyoshi H, Nakamura M (2007) Nanomedicine for drug delivery and imaging: A promising avenue for cancer therapy and diagnosis using targeted functional nanoparticles. Int J Cancer 120(12): 25272537.

59. Nel A, Xia T, Mädler L, Li N (2006) Toxic potential of materials at the nanolevel. Science 311(5761): 622-627.

60. Yigit MV, Moore A, Medarova Z (2012) Magnetic nanoparticles for cancer diagnosis and therapy. Pharm Res 29(5): 1180-1188.

61. Deepa V, Sridhar R, Goparaju A, Reddy PN, Murthy PB (2012) Nanoemulsifiedethanolic extract of Phyllanthusamarus Schum \&Thonn ameliorates $\mathrm{CCl} 4$ induced hepatotoxicity in Wistar rats. Indian J Exp Biol 50(11): 785-794.

62. Zhang J, Han X, Li X, Luo Y, Zhao H, et al. (2012) Core-shell hybrid liposomal vesicles loaded with panaxnotoginsenoside: preparation, characterization and protective effects on global cerebral ischemia/ reperfusion injury and acute myocardial ischemia in rats. Int J Nanomedicine 7: 4299-4310.

63. Shi F, Zhao JH, Liu Y, Wang Z, Zhang YT, et al. (2012) Preparation and characterization of solid lipid nanoparticles loaded with frankincense and myrrh oil. Int J Nanomedicine 7: 2033-2043.

64. Tetsuka T, Baier LD, Morrison AR (1996) Antioxidants inhibit inlerleukin-1-induced cyclooxygenase and nitric oxide synthase expression in rat mesangial cells. Evidence for post-transcriptional regulation. I BiolChem 271(20): 11689-11693.

65. Hempel SL, Monick MM, He B, Yano T, llunninghake GW (1994) Synthesis of prostaglandin $\mathrm{H}$ synthase-2 by human alveolar macrophages in response to lipopolysaccharidc is inhibited by decreased cell oxidant tone. I BiolChem 269(52): 32979-32984.

66. Coffey RJ, Hawkey CJ, Damstrup L, Deal R, Daniel VCet al (1997) Epidermal growth factor receptor activation induces nuclear targeting of cyclooxy genase-2. basolaleral release of prostaglandins and milogenesis in polari/ing colon cancer cells. Proc NatiAcad Sci USA 94: 657-662.

67. Hemaiswarya S, Doble M (2013) Combination of phenylpropanoids with 5-fluorouracil as anti-cancer agents against human cervical cancer (HeLa) cell line. Phytomedicine 20(2): 151-158.

68. Jaganathan SK, Supriyanto E (2012) Anti-proliferative and molecular mechanism of eugenol-induced apoptosis in cancer cells. Molecules 17(6): 6290-6204.

69. Wasser SP, Weis AL (1999) Medicinal properties of substances occurring in higher Basidiomycete mushrooms: current perspectives (review). Int J Med Mushrooms 1: 47-50.

70.Shklar G, Schwartz J, Trickler D, Reid S (1989) Regression of experimental cancer by oral administration of combined alphatocopherol and beta-carotene. Nutr Cancer 12(4): 321-325. 
This work is licensed under Creative Commons Attribution 4.0 License

DOI: 10.19080/GJN.2017.02.555595
Your next submission with JuniperPublishers will reach you the below assets

- Quality Editorial service

- Swift Peer Review

- Reprints availability

- E-prints Service

- Manuscript Podcast for convenient understanding

- Global attainment for your research

- Manuscript accessibility in different formats

( Pdf, E-pub, Full Text, Audio)

- Unceasing customer service

Track the below URL for one-step submission https://juniperpublishers.com/submit-manuscript.php 